\title{
Erratum to: Bacteria can promote calcium oxalate crystal growth and aggregation
}

\author{
Somchai Chutipongtanate - Suchitra Sutthimethakorn • \\ Wararat Chiangjong • Visith Thongboonkerd
}

Published online: 20 March 2013

(C) SBIC 2013

Erratum to: J Biol Inorg Chem (2013) 18(3):299-308

DOI 10.1007/s00775-012-0974-0

The original publication of the article contained errors in the labels of significant differences among groups in Figs. $4 \mathrm{~b}$ and $5 \mathrm{~b}$.

The revised figures are given below.

The online version of the original article can be found under doi:10.1007/s00775-012-0974-0.

S. Chutipongtanate $\cdot$ S. Sutthimethakorn - W. Chiangjong ·

V. Thongboonkerd $(\bowtie)$

Medical Proteomics Unit, Office for Research and Development,

Faculty of Medicine Siriraj Hospital,

Center for Research in Complex Systems Science,

Mahidol University, 6th Floor-SiMR Building,

2 Prannok Road, Bangkoknoi, Bangkok 10700, Thailand

e-mail: thongboonkerd@dr.com; vthongbo@yahoo.com 

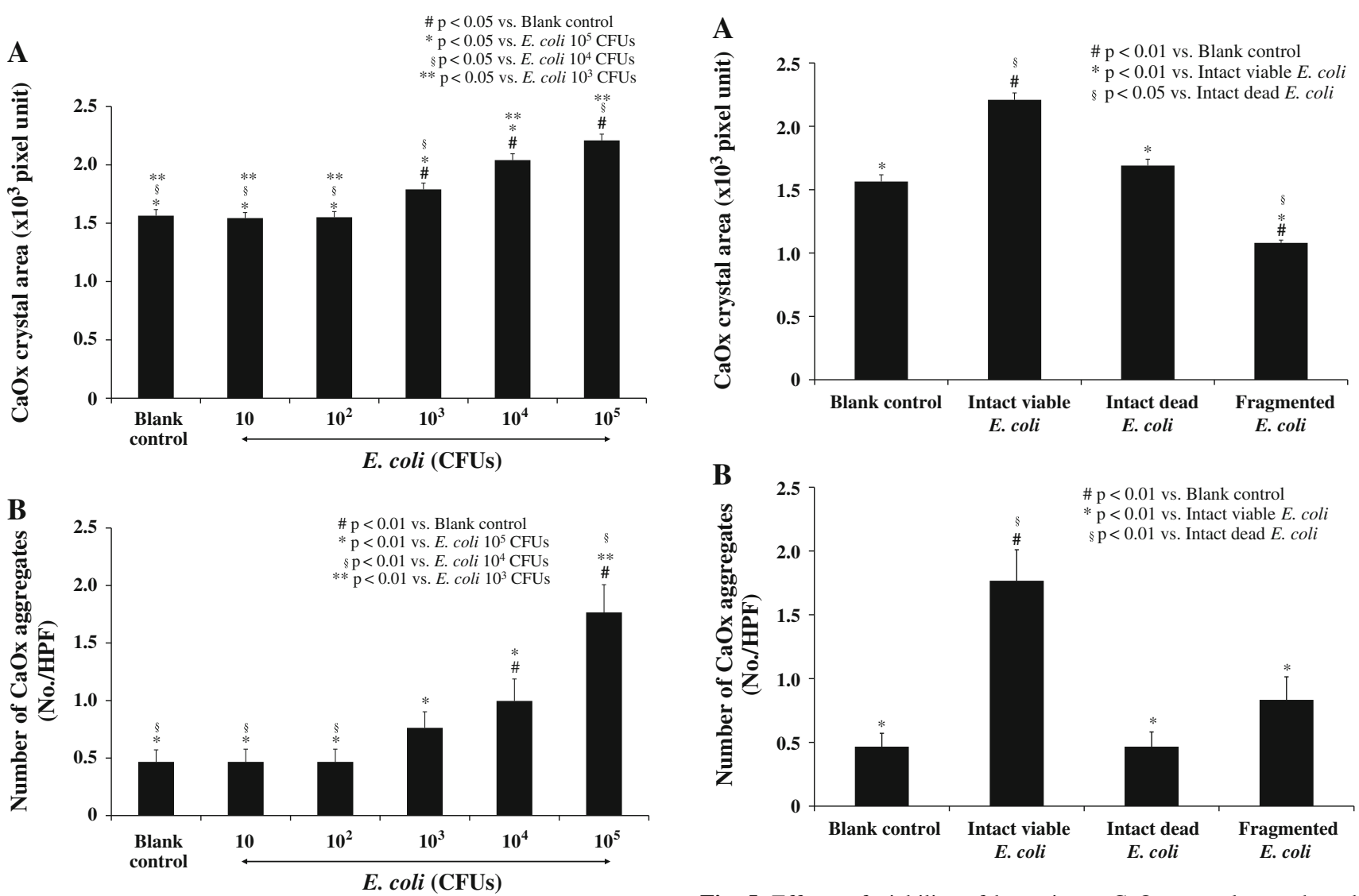

Fig. 4 Effects of differential doses of bacteria on $\mathrm{CaOx}$ crystal growth and aggregation. $\mathrm{CaOx}$ crystals were generated in the absence (blank control) or presence of $10-10^{5} \mathrm{CFUs} / \mathrm{ml}$ of E. coli. The crystal area (a) and number of crystal aggregates (b) were then analyzed. Each bar was derived from three independent experiments and the data are reported as mean \pm SEM

Fig. 5 Effects of viability of bacteria on $\mathrm{CaOx}$ crystal growth and aggregation. $\mathrm{CaOx}$ crystals were generated in the absence (blank control) or presence of $10^{5} \mathrm{CFUs} / \mathrm{ml}$ of intact viable, intact dead or fragmented E. coli. The crystal area (a) and number of crystal aggregates (b) were then analyzed. Each bar was derived from three independent experiments and the data are reported as mean \pm SEM 